\title{
Mass Analysis of Silver-Carbon Mixed Cluster Ions Produced by Fast Atom Bombardment
}

\author{
Chikara Amano and Hiroshi IshigakI \\ Department of Materials Science, Faculty of Science, Kanagawa University, \\ Tsuchiya, Hiratsuka, Kanagawa 259-12, Japan
}

\begin{abstract}
A regular series of silver-carbon mixed cluster ions: $\mathrm{Ag}_{m} \mathrm{C}_{2 n}(m=3,5,7,9 ; n=1,2,3)$ has been found by mass spectrometry. This regularity is not destroyed by the energetic collisions of the cluster ions with argon atoms. Remarkable differences are observed in the chemical species produced between the cluster ions containing odd numbers of silver atoms and those containing even numbers of silver atoms. Size-selected reactions of the cluster ions with argon clearly show the magic numbers effect, in addition to the even-odd difference. The mechanism of formation of silver-carbon mixed cluster ions is studied. The authors propose that the mixed cluster ions are produced on a silver surface through decomposition and dehydrogenation of hydrocarbon molecules contained in the background gas of the ionization chamber. This picture is consistent with observations from scanning tunneling microscopy.
\end{abstract}

Keywords Cluster, silver-carbon, mass spectrometry, catalysis

For clusters of alkali metals and coinage metals, the existence of magic numbers, the number of atoms contained in a cluster which is assumed to be more stable, has been widely known. ${ }^{1,2}$ During experiments to find the magic numbers for various substances, a regular series of silver-carbon mixed cluster ions has been found. The regularity was not destroyed by the energetic collisions of the cluster ions with argon atoms. Recently, much interest has been taken in metal-carbon cluster compounds. Titanium-carbon and zirconium-carbon clusters with novel cage-like structures have been found. 3,4

The chemistry of clusters provides a model for understanding the mechanism of an inhomogeneous catalytic reaction on a solid surface. Metallic silver works as a good catalyst for partial oxidation of ethylene to ethylene oxide. The silver-carbon mixed cluster ions and the silver-oxygen mixed cluster ions observed here may serve to build a model of the mechanism of the catalytic reaction. Quite recently, related results on the formation of the graphite structure on a surface of gold or platinum have been reported by the use of scanning tunneling microscopy (STM)..$^{5-7}$

\section{Experimental}

(1) Mass spectra of silver cluster ions and silver-carbon mixed cluster ions were obtained by the double focusing mass spectrometer (JEOL Co., JMS-AX505H) with the FAB (xenon atoms) ionization technique. Metallic silver (sheet) was attached directly to a sample holder for
FAB ionization without using matrix compounds. (2) Reactions of the mass-analyzed cluster ions (size-selected reaction) were measured; mass spectra of daughter ions produced through the dissociation of a parent ion in metastable states, which was produced by the energetic $(3 \mathrm{keV})$ collisions with argon atoms, were measured by the B/E-linked scan technique. (3) The mechanism of formation of the silver-carbon mixed cluster was studied. The change in the abundance of the cluster ions was monitored with the period of xenon beam bombardment. To identify the molecules producing the mixed cluster ions, reactions of metallic silver with several kinds of gas containing carbon atoms were studied. The gas was introduced through a short capillary from the orifice for the gas chromatograph into the ionization chamber of the mass spectrometer.

\section{Results and Discussion}

\section{Mass spectra of silver-carbon mixed cluster ions}

A regular series of silver-carbon mixed cluster ions is observed in the mass spectrum of Fig. 1. Each component shows a characteristic multiplet structure due to the different contents of isotopes of silver. Since elemental silver is composed of nearly equal amounts of isotopes with mass numbers 107 and 109, the mass spectrum of a silver cluster ion shows a multiplet structure, depending on the number of silver atoms contained in it, with components proportional to the binomial coefficients. This multiplet structure is useful for the identification of bare silver cluster ions and mixed 


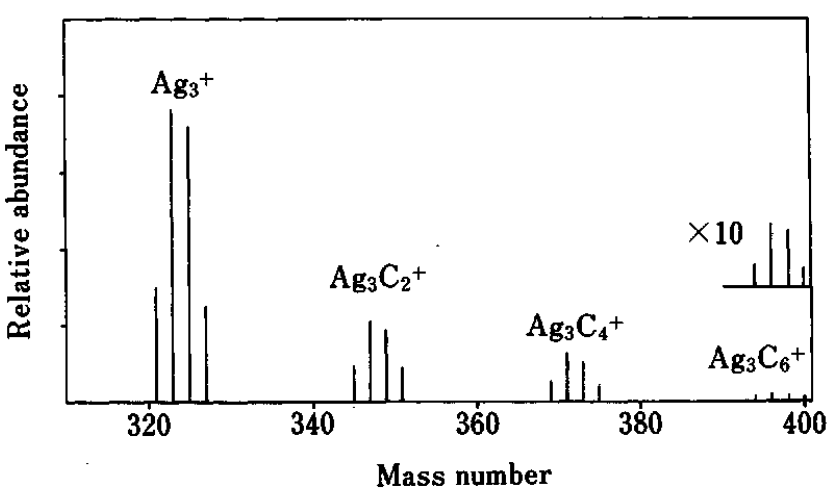

Fig. 1 Part of mass spectrum of bare silver and silver-carbon mixed cluster ions measured by FAB ionization.

Table 1 Positive silver cluster ions (cluster ions with odd numbers of atoms)

\begin{tabular}{|c|c|c|c|}
\hline Bare metal & $\mathrm{C}_{2}$ & $\mathrm{C}_{4}$ & $\mathrm{C}_{6}$ \\
\hline $\mathrm{Ag}^{+} \quad(100)$ & & & \\
\hline $\mathrm{Ag}_{3}+(100)$ & $\mathrm{Ag}_{3} \mathrm{C}_{2}+(30)$ & $\mathrm{Ag}_{3} \mathrm{C}_{4}+(15)$ & $\mathrm{Ag}_{3} \mathrm{C}_{6}+(2)$ \\
\hline $\mathrm{Agg}^{+}(100)$ & $\mathrm{Ag}_{5} \mathrm{C}_{2}+(20)$ & $\mathrm{Ag}_{5} \mathrm{C}_{4}+(15)$ & $\mathrm{Ag}_{5} \mathrm{C}_{6}+(2)$ \\
\hline $\mathrm{Ag}_{7}+(100)$ & $\mathrm{Ag}_{7} \mathrm{C}_{2}+(10)$ & $\mathrm{Ag}_{7} \mathrm{C}_{4}+$ & $\mathrm{Ag}_{7} \mathrm{C}_{6}+(2)$ \\
\hline $\mathrm{Ag}_{9}+(100)$ & $\mathrm{Ag}_{9} \mathrm{C}_{2}+(10)$ & $\mathrm{Ag}_{9} \mathrm{C}_{4}+$ & $\mathrm{Ag}_{9} \mathrm{C}_{6}+(1)$ \\
\hline $\mathrm{Ag}_{11}+(100)$ & $\mathrm{Ag}_{11} \mathrm{C}_{2}{ }^{+}(10)$ & & \\
\hline
\end{tabular}

Numbers in parentheses are the abundance relative to the bare silver cluster ion with each number of atoms.

Table 2 Positive silver cluster ions (cluster ions with even numbers of atoms)

\begin{tabular}{cccc}
\hline Bare metal & $\mathrm{H}$ & $\mathrm{OH}$ & $\mathrm{C}_{2} \mathrm{H}_{2}$ \\
\hline $\mathrm{Ag}_{2}{ }^{+}(100)$ & $\mathrm{Ag}_{2} \mathrm{H}^{+}(15)$ & $\mathrm{Ag}_{2} \mathrm{OH}^{+}(15)$ & $\mathrm{Ag}_{2} \mathrm{C}_{2} \mathrm{H}_{2}{ }^{+}(70)$ \\
$\mathrm{Ag}_{4}+(100)$ & & $\mathrm{Ag}_{4} \mathrm{OH}^{+}(30)$ & $\mathrm{Ag}_{4} \mathrm{C}_{2} \mathrm{H}_{2}{ }^{+}(30)$ \\
$\mathrm{Ag}_{6}+(100)$ & & $\mathrm{Ag}_{6} \mathrm{OH}^{+}(15)$ & \\
\hline
\end{tabular}

Numbers in parentheses are the abundance relative to the bare silver cluster ions with each number of atoms.

silver cluster ions. The identified cluster ions are summarized in Tables 1 and 2. The figures in the Tables stand for the relative abundances of the mixed cluster ions to the bare silver cluster ions with an equal number of silver atoms.

Remarkable differences are observed between cluster ions containing odd numbers of silver atoms and those containing even numbers of silver atoms. The clusters containing odd numbers of silver atoms produce a regular series of silver-carbon mixed cluster ions of the formula $\mathrm{Ag}_{m} \mathrm{C}_{2 n}{ }^{+}$( $m$ is an odd number from 3 to 11 , and $n=1,2$, or 3 ). These cluster ions contain no hydrogen atoms. That carbon atoms are contained always in pairs in the mixed cluster ions may suggest the formation of a chemical bond between carbon atoms (possibly a double or triple bond). On the other hand, the cluster ions containing even numbers of silver atoms bind $\mathrm{OH}$ or $\mathrm{C}_{2} \mathrm{H}_{2}$ radicals. Related to this difference, the phenomenon of even-odd alterations in strength has been observed
Table 3 Negative silver cluster ions

\begin{tabular}{|c|c|c|}
\hline Bare metal & $\mathrm{O}$ & \\
\hline $\mathrm{Ag}_{4}^{-}(100)$ & $\mathrm{Ag}_{4} \mathrm{O}^{-}(250)$ & \\
\hline $\mathrm{Ag}_{6}-(100)$ & $\mathrm{Ag}_{6} \mathrm{O}^{-}(150)$ & \\
\hline $\mathrm{Ag}_{8}^{-}(100)$ & $\mathrm{Ag}_{8} \mathrm{O}^{-}(150)$ & \\
\hline $\mathrm{Ag}_{10^{-}}(100)$ & $\mathrm{Ag}_{10} \mathrm{O}^{-}(60)$ & \\
\hline $\mathrm{Ag}_{12^{-}}(100)$ & $\mathrm{Ag}_{12} \mathrm{O}^{-}$ & \\
\hline $\mathrm{Ag}_{14^{-}}(100)$ & $\mathrm{Ag}_{14} \mathrm{O}^{-}(20)$ & \\
\hline $\mathrm{Ag}_{3}^{-}(100)$ & $\mathrm{Ag}_{3} \mathrm{C}_{2}-(10)$ & $\mathrm{Ag}_{3} \mathrm{C}_{4}^{-}(5)$ \\
\hline
\end{tabular}

Numbers in parentheses are the abundance relative to the bare silver cluster ions with each number of atoms.

in the mass spectra of bare silver cluster ions. ${ }^{1,9}$ The cluster ions containing odd numbers of silver atoms are more abundant than those containing even numbers of silver atoms. Another feature of the mass spectra of bare silver cluster ions is the existence of magic numbers $3,9,19,21,35,41,59,69, \cdots$ The cluster ions containing these numbers of silver atoms are abundant in mass spectra and are assumed to be more stable. Among silver-carbon mixed cluster ions, $\mathrm{Ag}_{3} \mathrm{C}_{2 n}{ }^{+}$and $\mathrm{Ag}_{9} \mathrm{C}_{2 n}{ }^{+}$are more abundant than the other mixed cluster ions; so the numbers 3 and 9 may be assumed to be magic numbers.

The even-odd differences observed in the formation of positive silver-carbon mixed cluster ions were also observed in the mass spectra of negative cluster ions. The negative cluster ions identified are summarized in Table 3. In contrast to the positive ions, the negative ions containing even numbers of silver atoms produce silver-oxygen mixed cluster ions of the formula $\mathrm{Ag}_{m} \mathrm{O}^{-}$ ( $m=$ even numbers from 4 to 14). For cluster ions containing odd numbers of silver atoms, no mixed cluster ions are observed though they are more abundant than those containing even numbers of silver atoms. The exception is the formation of $\mathrm{Ag}_{3} \mathrm{C}_{2}^{-}$and $\mathrm{Ag}_{3} \mathrm{C}_{4}^{-}$. This may be a manifestation of the magic numbers effect. The observation of $\mathrm{Ag}_{m} \mathrm{C}_{2 n}{ }^{+}$in the mass spectra of positive ions and $\mathrm{Ag}_{m} \mathrm{O}^{-}$in the mass spectra of negative ions may serve to build a model for the mechanism of catalytic reaction of silver in partial oxidation of ethylene to ethylene oxide.

The even-odd difference observed in both positive and negative cluster ions could be seen beyond the mass ranges in Tables 1, 2, and 3, but the identification of the ions could not be done because of the depletion of intensity.

\section{Size-selected reaction of silver cluster ions}

Reactions of mass selected bare silver cluster ions or mixed silver cluster ions, which contain a certain number of silver atoms, clearly show the magic numbers effect, in addition to the even-odd difference. The regular series of silver-carbon mixed cluster ions is not destroyed through these reactions. All daughter ions produced from a parent cluster ion are summarized in Table $\mathbf{4}$ for mixed cluster ions and in Table 5 for bare silver cluster ions. Figures in the Tables show relative abundances of 
Table 4 Decomposition of clusters through collisional activation (silver carbon cluster)

\begin{tabular}{|c|c|c|c|}
\hline Parent $\left(m_{1}^{+}\right)$ & & aughter $\left(\mathrm{m}_{2}{ }^{+}\right)$ & \\
\hline $\mathrm{Ag}_{3} \mathrm{C}_{2}^{+}$ & $\mathrm{Ag}_{2} \mathrm{C}_{2}+$ & $\mathrm{Ag}_{2}{ }^{+}$ & \\
\hline $\mathrm{Ag}_{3} \mathrm{C}_{4}{ }^{+}$ & $\mathrm{Ag}_{3}{ }^{+} \quad(10)$ & $\mathrm{Ag}_{2} \mathrm{C}_{4}+$ & $\mathrm{Ag}_{2}^{+}$(5) \\
\hline $\mathrm{Ag}_{5} \mathrm{C}_{2}+$ & $\mathrm{Ag}_{3} \mathrm{C}_{2}+(40)$ & $\mathrm{Ag}_{3}{ }^{+} \quad$ (20) & \\
\hline $\mathrm{Ag}_{5} \mathrm{C}_{4}{ }^{+}$ & $\mathrm{Ag}_{3} \mathrm{C}_{4}+(50)$ & $\mathrm{Ag}_{3} \mathrm{C}_{2}+(50)$ & $\mathrm{Ag}_{3}+(20)$ \\
\hline $\mathrm{Ag}_{7} \mathrm{C}_{2}{ }^{+}$ & $\mathrm{Ag}_{3} \mathrm{C}_{2}+(30)$ & & \\
\hline
\end{tabular}

Numbers in parentheses are the abundance relative to the parent cluster ions with each number of atoms.

Table 5 Decomposition of cluster ions through collisional activation (pure silver cluster ions)

\begin{tabular}{cll}
\hline Parent $\left(m_{1}{ }^{+}\right)$ & \multicolumn{2}{c}{ Daughter $\left(m_{2}{ }^{+}\right)$} \\
\hline $\mathrm{Ag}_{3}{ }^{+}$ & $\mathrm{Ag}_{2}{ }^{+}(6)$ & $\mathrm{Ag}^{+}(2)$ \\
$\mathrm{Ag}_{5}{ }^{+}$ & $\mathrm{Ag}_{4}{ }^{+}(10)$ & $\mathrm{Ag}_{3}{ }^{+}(60)$ \\
$\mathrm{Ag}_{9}{ }^{+}$ & $\mathrm{Ag}_{8^{+}}(10)$ & \\
$\mathrm{Ag}_{2}{ }^{+}$ & $\mathrm{Ag}^{+}(5)$ & \\
$\mathrm{Ag}_{4}{ }^{+}$ & $\mathrm{Ag}_{3}{ }^{+}(15)$ & \\
$\mathrm{Ag}_{6}{ }^{+}$ & $\mathrm{Ag}_{5}{ }^{+}(40)$ & $\mathrm{Ag}_{3}{ }^{+}(15)$ \\
$\mathrm{Ag}_{8}{ }^{+}$ & $\mathrm{Ag}_{7^{+}}(3)$ & \\
\hline
\end{tabular}

Numbers in parentheses are the abundance relative to the parent cluster ions with each number of atoms.

the daughter ions to the parent ions remained. The pair of carbon atoms characteristic of silver-carbon mixed cluster ions is not destroyed even through the reactions. The cluster ions with a magic number, $\mathrm{Ag}_{3} \mathrm{C}_{2}{ }^{+}$and $\mathrm{Ag}_{3} \mathrm{C}_{4}{ }^{+}$, do not dissociate appreciably, so they are observed in abundance in dissociation products. For bare silver cluster ions, the cluster ions with magic numbers, $\mathrm{Ag}_{3}{ }^{+}$and $\mathrm{Ag}_{9}{ }^{+}$, do not dissociate, so they are observed in greater amounts in reaction products. The cluster ions with quasi-magic numbers (the number of ion cores, instead of the number of valence electrons, is a magic number), $\mathrm{Ag}_{2}{ }^{+}$and $\mathrm{Ag}_{8}{ }^{+}$, do not dissociate appreciably. The even-odd difference is observed also in dissociation products. The daughter ions with odd numbers of silver atoms are much more abundant in dissociation products.

\section{Mechanism of formation of silver-carbon mixed cluster ions}

A series of silver-carbon mixed cluster ions is produced in a high vacuum of the ionization chamber $\left(5 \times 10^{-3} \mathrm{~Pa}\right)$ without any reactive gas being added intentionally. The mechanism of formation of the mixed cluster ions was studied. Figure 2 shows the change in the abundance of the mixed cluster ions with the varying period for the bombardment of xenon beam. A speculation is examined that the silver-carbon mixed cluster ions are produced continually in a high vacuum of the ionization chamber. Unless the mixed cluster ions are continuously produced in a high vacuum of the ionization chamber, the intensity of the mixed cluster ions should decrease with the period for the bombardment of xenon atoms, since they should disappear gradually upon the

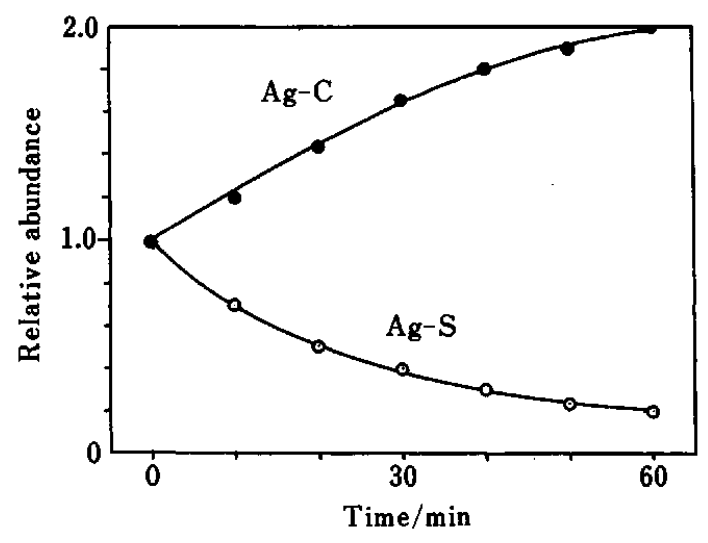

Fig. 2 Change of relative abundances of silver-carbon and silver-sulfur mixed cluster ions with time for the bombardment of xenon atomic beam.

bombardment of xenon atoms. To confirm this speculation, a comparison is made for silver-carbon mixed cluster ions and silver-sulfur mixed cluster ions. The silver-sulfur mixed cluster ions emerge from a thin film of sulfide on a surface of metallic silver which is produced through the reaction with hydrogen sulfide in the air. The intensity of the silver-sulfur mixed cluster ions decreases with time, as shown in Fig. 2. Similar decrease in intensity has been reported for manganeseoxygen mixed clusters. ${ }^{8}$ For the silver-carbon mixed cluster ions, however, the intensity increases as the period for the bombardment of xenon atoms lengthens. This observation confirms the above speculation that the silver-carbon mixed cluster ions are continuously produced in a high vacuum of the ionization chamber. The silver-carbon mixed cluster ions may emerge from a thin film of carbon on a silver surface formed through decomposition and dehydrogenation of some hydrocarbons contained in the background gas of the ionization chamber. The increase in intensity of the silver-carbon mixed cluster shown in Fig. 2 may be due to the rise in temperature of the silver specimen. The temperature of the specimen is increased by the bombardment of an energetic xenon atomic beam so that the rate for the formation of a carbon thin film on the surface of silver also increases. The mechanism of formation of the silver-carbon mixed cluster ions proposed here is consistent with observations by STM of the formation of graphite structure on a gold or platinum surface in a high vacuum. 5,6

\section{Disappearance of silver-carbon mixed cluster ions}

The above experiments cannot identify molecular species which react with metallic silver and produce the silver-carbon mixed cluster ions. To identify the molecular species, reactions were examined of silver with several kinds of gas introduced in the ionization chamber up to a pressure of $0.04 \mathrm{~Pa}$. Since silver-carbon mixed cluster ions contain carbon atoms in pairs, ethylene with a backbone of $\mathrm{C}_{2}$ is thought to be effective for the production of the mixed ions. However, it is not 
effective for the increase in the abundance of the mixed cluster ions. This result appears to contradict with results obtained by STM. But this contradiction is superficial, since MS is a destructive analytical instrument and STM is a non-destructive analytical one. In MS observation of the silver-carbon mixed cluster ions is difficult unless they are continually produced during observation. Introduction of methane or carbon dioxide is ineffective for the production of the mixed cluster ions. When carbon monoxide is introduced at a pressure of $0.04 \mathrm{~Pa}$, the silver-carbon mixed cluster ions disappear almost completely and only bare silver cluster ions remain. Further experiments to study this unexpected phenomenon are in progress where effects on the formation of the silver-carbon mixed cluster ions by the change of the pressure of carbon monoxide, or by the change of the period from introduction of carbon monoxide to observation of the mixed clusters are examined. The phenomenon of disappearance of mixed cluster ions is useful to simplify mass spectra. Further experiments are in progress on the identification of molecular species producing the silver-carbon mixed cluster ions.

\section{References}

1. W. D. Knight, K. Clemenger, W. A. de Heer, W. A. Saunders, M. Y. Chou and M. L. Cohen, Phys. Rev. Lett., 52, 2141 (1984).

2. I. Katakuse, T. Ichihara, Y. Fujita, T. Matsuo, T. Sakurai and H. Matsuda, Int. J. Mass Spectrom. Ion Processes, 67, 229 (1985).

3. B. C. Guo, K. P. Kems and A. W. Castleman, Jr., Science [Washington, D.C.], 255, 1411 (1992).

4. S. Wei, B. C. Guo, J. Purnell, S. Buzza and A. W. Castleman, Jr., Science [Washington, D.C.], 256, 818 (1992).

5. T. A. Land, T. Michely, R. J. Behm, J. C. Hemminger and G. Comsa, Appl. Phys., A, 53, 414 (1991).

6. T. A. Land, T. Michely, R. J. Behm, J. C. Hemminger and G. Comsa, Surf. Sci, 264, 261 (1992).

7. E. Ganz, K. Sattler and J. Clarke, Surf. Sci, 219, 33 (1989).

8. Y. Saito, H. Ito and I. Katakuse, Z. Phys. D, 19, 189 (1991).

9. G. Hortig and M: Muller, Z. Phys., 221, 119 (1969).

(Received August 3, 1993)

(Accepted November 25, 1993) 